\title{
Aspectos para compreender o peculiar sistema monetário cubano
}

\author{
Aspects to understand the peculiar \\ cuban monetary system
}

DOI: 10.5752/P.2317-773X.2018v6.n3.p118

1. Economista, doutor em Economia pela Universidade Federal Fluminense (UFF/ RJ). Atualmente é professor adjunto IV e vice coordenador do curso de Ciências Econômicas da Universidade Federal Rural do Rio de Janeiro (UFRRJ), ConseIheiro do Conselho Federal de Economia (COFECON) e Conselheiro do Conselho

Regional de Economia do Rio de Janeiro (CORECON-RJ). Membro do Conselho Consultivo do Centro Brasileiro de

Solidariedade aos Povos e Luta pela Paz (CEBRAPAZ). Rio de Janeiro/Brasil ORCID ID: 0000-0003-4550-8564

2. Mestre em Desenvolvimento Econômico pelo Instituto de Economia da Universidade Estadual de Campinas. Professora Assistente e coordenadora do curso de Ciências Econômicas da Universidade Federal Rural do Rio de Janeiro (UFRRJ). Bolsista de Extensão no País SA. Foi bolsista do IPEA (PRO$\mathrm{MOB})$ no projeto "Estrutura Socioeconômica e Políticas para a Integração

da América do Sul". Participou do projeto "Perspectivas do Investimento no Brasil" (BNDES) com o tema "Perspectiva do Investimento na dimensão do

Mercosul e da Integração da América Latina. Rio de Janeiro/Brasil ORCID ID : 0000-0002-4824-8414

3. Graduada em Relações Internacionais pela Universidade Federal Rural do

Rio de Janeiro (UFRRJ) e membro do Conselho Fiscal do Centro Brasileiro de Solidariedade aos Povos e Luta pela Paz (CEBRAPAZ). São Paulo/Brasil ORCID ID: 0000-0002-8497-523X

\author{
Marcelo Pereira Fernandes ${ }^{1}$ \\ Rubia Wegner $^{2}$ \\ Pamela Martins ${ }^{3}$
}

Submetido em: 24 de dezembro de 2017

Aprovado em: 18 de junho de 2018

\section{Resumo}

O sistema monetário cubano apresenta atualmente duas moedas nacionais, o peso (CUP) e o peso conversível (CUC), emitidas pelo banco central, e que circulam legalmente no país. Este trabalho procura analisar os principais aspectos desse processo, considerado único e que foi originado pela mais grave crise econômica da história de Cuba. Para isso, foi necessário um resgate da conjuntura que levou o governo a desenvolver esse sistema, apontando suas características e seu funcionamento. Apesar do sucesso em estabilizar a economia, a circulação de duas moedas oficiais gerou distorções sociais graves relacionadas ao consumo de mercadorias, entre aqueles com acesso e sem acesso ao peso conversível. Entendemos que a singularidade do sistema monetário cubano já teria cumprido sua função histórica. A questão está em realizar a unificação monetária sem recriar os problemas enfrentados pelo país nos anos 1990, algo essencial para que o país possa tirar o melhor proveito de uma possível normalização das relações econômicas com os Estados Unidos.

Palavras-Chave: Cuba, crise, dolarização, peso conversível, dualidade.

\section{AbSTRACT}

The Cuban monetary system currently has two national currencies, peso (CUP) and the convertible peso (CUC), issued by the central bank, which circulate legally in the country. This paper analyzes the main aspects of this process, considered unique that was originated by the most serious economic crisis in the history of Cuba. For this, a rescue of the situation was necessary that prompted the government to develop this system, indicating their characteristics and functioning. Despite the success in stabilizing the economy, the circulation of two official currencies has generated serious social distortions related to the consumption of goods between those with access and without access to the convertible peso. We understand that the uniqueness of the Cuban monetary system has already fulfilled its historical function. The point is to achieve a monetary unification without recreating the problems faced by the country in the 1990s, something essential for the country to make the best use of a possible normalization of economic relations with the United States.

Keywords: Cuba, crisis, dollarization, convertible peso, duality. 
Introdução

No dia $1^{\circ}$ de julho de 2015 o então presidente Barack Obama anunciou formalmente o restabelecimento das relações diplomáticas plenas com Cuba, materializada na reabertura da embaixada cubana em Washington no dia 20 de julho (PECEQUILO; FORNER, 2015). O ato histórico foi comemorado pelas autoridades cubanas que vislumbraram com esse acontecimento o fim do embargo econômico em vigência contra a Ilha há mais de 50 anos. Sob essa perspectiva grandes empresas norte-americanas passaram a operar em Cuba, como a Google, American Express, Netflix, Airbnb, entre outras. O governo de Obama de fato tornou as relações diplomáticas entre os Estados Unidos e Cuba menos agressivas, ainda que na prática o bloqueio não tenha sido revogado ou mesmo relativizado. Entretanto, essa postura vem se modificando com o atual presidente Donald Trump.

De qualquer forma, Cuba enfrenta vários problemas econômicos domésticos a serem resolvidos para que o país possa tirar o melhor proveito de uma normalização das relações econômicas (reduzir sua restrição externa, diversificar sua pauta exportadora etc.) que possivelmente ocorrerá num futuro não tão distante. Em especial, a questão do sistema monetário dual, no qual o país convive com a emissão pelo Banco Central Cubano (BCC) de duas moedas de curso forçado, é um desafio que as autoridades cubanas estão enfrentando.

O sistema monetário cubano dual é fruto do processo de dolarização que a economia cubana experimentou após a dissolução da União Soviética ocorrida em agosto de 1991. Na realidade, durante os anos 1980 vários países latino-americanos que sofreram com a hiperinflação foram forçados a passar pela experiência de ter sua economia dolarizada ou parcialmente dolarizada. A dolarização é um fenômeno que acontece quando a moeda de referência da economia nacional é substituída nas transações, pelas famílias e empresas por dólar. A dolarização parcial refere-se a uma situação em que a moeda estrangeira atende pelo menos uma de suas funções em uma economia em que a moeda nacional também circula, ainda que parte considerável dos ativos públicos e privados seja expressa em moeda estrangeira. Neste caso, dizemos que a economia está dolarizada parcialmente porque ainda existe um Banco Central que emite moeda corrente nacional. Na dolarização total a moeda nacional simplesmente desaparece e uma moeda estrangeira, o dólar, passa a cumprir todas as funções. Este foi o caso do Equador quando, em 2000, para interromper uma hiperinflação o sucre foi oficialmente substituído pelo dólar. Nesse caso, o Banco Central perde completamente a autonomia da política monetária. Há ainda os casos como o do Panamá que, embora exista uma moeda nacional, a balboa panamenha, a moeda que circula de fato é o dólar. A maioria das experiências é de dolarização parcial, em particular na América Latina. O exemplo cubano do começo dos anos 1990 também é de dolarização parcial, visto que o governo sempre emitiu a moeda nacional, o peso. Como em todos os casos de dolarização, a origem do caso cubano se encontra em uma grave crise econômica, e nos profundos desequilíbrios macroeconômicos derivados dessa crise. De tal modo, Cuba passou a conviver com duas moedas legais 
4. O COMECON reunia o bloco dos países socialistas, liderados pela União Soviética. 0 ingresso no Conselho possibilitou para a economia cubana uma nova fronteira econômica. 0 COMECON promovia ações coordenadas de política econômica entre os países membros, que se traduziam em planos quinquenais (Cf. CEPAL, 2000). Antes de 1959, 0 comércio com os países socialistas era quase inexistente. (PÉREZ, 1983).

5. Vale lembrar que desde o início da Perestroika e da Glasnost na segunda metade dos anos 1980, a relação entre os dois países vinha se deteriorando. Mikhail Gorbachev dava sinais claros que já não desejava manter Cuba como parceiro comercial privilegiado. Isso se refletiu na redução do comércio bilateral já nesse período. (GARCÍA, 2013; PÉREZ, JR, 2006)

6. Cuba enfrentou um problema similar em 1960, quando os Estados Unidos cortaram relações comercias e o país teve que buscar uma nova forma de inserção na economia mundial (CHANG, 2013). de curso forçado, caracterizando a originalidade do sistema. A experiência cubana é ainda mais curiosa por se tratar de uma engenharia monetária inédita, realizada em um país com um sistema financeiro pouco desenvolvido, mesmo se tratando de uma economia planificada. Realmente um experimento monetário excepcional.

Assim, o objetivo deste artigo é avaliar o contexto em que surgiu a dualidade monetária em Cuba e os fatores que explicam sua permanência. Trata-se de um processo singular originado pela mais grave crise econômica da história de Cuba. E por se tratar de uma experiência peculiar é bastante difícil prever as consequências econômicas e políticas que a saída do sistema acarretará. Além dessa introdução, o artigo está dividido em mais quatro seções. Na próxima seção, discutiremos o processo de dolarização em Cuba durante o "Período Especial". Na terceira seção, analisaremos a resposta que as autoridades cubanas encontraram para enfrentar o problema da dolarização que, como veremos, entre outras medidas, consistiu na legalização do dólar e na criação de mais uma moeda oficial. Além do peso (CUP), foi criado o denominado peso conversível (CUC), uma moeda que, na prática, só é conversível dentro do mercado cubano. Na quarta seção, discutiremos as medidas adotadas pelo governo no começo dos anos 2000 que se consubstanciaram numa ampliação do uso do CUC. E, por fim, seguem as considerações finais.

\section{Economia cubana: período especial}

Por quase três décadas, a partir da Revolução de 1959, Cuba manteve uma relação de estreita dependência com a União Soviética, sustentada por meio do abastecimento de insumos estratégicos, como o petróleo usado na produção de energia em suas termoelétricas, e por meio da absorção da produção de açúcar cubano pelo mercado soviético, incluindo a inserção do país no Conselho para Assistência e Econômica Mútua (COMECON) em 1972. ${ }^{4}$

Com o fim da Guerra Fria e da União Soviética em 19915, Cuba presenciou um cenário internacional extremamente desfavorável, em que os seus principais parceiros comerciais que formavam o COMECON já não estavam dispostos a manter o regime de acordos preferenciais. Isso representou para o país a perda de forma súbita de seus mercados consumidores e fornecedores, o que fez com que se registrasse uma queda na sua corrente de comércio em torno de $80 \%{ }^{6}$ (CHOMSKY, 2015; GARCIA, 2011). Na mesma época, as condições do mercado mundial para Cuba pioraram substancialmente com o aumento no preço do petróleo e a queda nos preços do açúcar (PÉREZ, JR, 2006). Além do que, os saldos comerciais deficitários que Cuba acumulava com a União Soviética constituíram uma dívida com a recém-criada Federação Russa, que passou a exigir o seu pagamento. E como o uso do dólar era proibido e a maior parte do comércio era realizada com os países do COMECON por meio de acordos creditícios (PÉREZ, 1983), embora não tenhamos dados disponíveis é razoável supor o estoque de reservas em moeda conversível eram insignificantes diante da restrição externa que o país enfrentaria. 
Como resultado, o país mergulhou na mais severa crise econômica desde a revolução, em 1959. Houve uma grave escassez de produtos para o consumo final, prejudicando diretamente a qualidade de vida, além da escassez de matérias-primas que freou a produção industrial, deixando o cenário do comércio externo ainda mais difícil. O consumo de combustíveis, por exemplo, caiu pela metade, produzindo assim um círculo vicioso (BCC, 2001). Além do comércio, os impactos negativos ficam evidentes quando se verifica alguns indicadores macroeconômicos do país. Os dados do Gráfico 1 sugerem que de 1989 a 1993 o PIB diminuiu cerca de um terço de seu tamanho, as importações diminuíram 78\%, e em 1993 o déficit fiscal alcançou 33,5\% do PIB. Só em 1991, o PIB recuou 10,7\% (BCC, 2001). Portanto, tratou-se de uma crise tão profunda que torna surpreendente a própria permanência do Partido Comunista de Cuba (PCC) no poder durante esse processo.

Os efeitos da crise são descritos nos Gráficos 1,2 e 3. As possibilidades dos gastos públicos terem algum efeito positivo sobre o crescimento econômico minguaram após o fim da URSS $^{7}$ (Gráfico 2) ao mesmo tempo em que, somente em 2011, o país conseguiu ultrapassar o nível de exportações de 1990 (Gráfico 3).

Gráfico 1 - Produto Interno Bruto (PIB)- \% anual

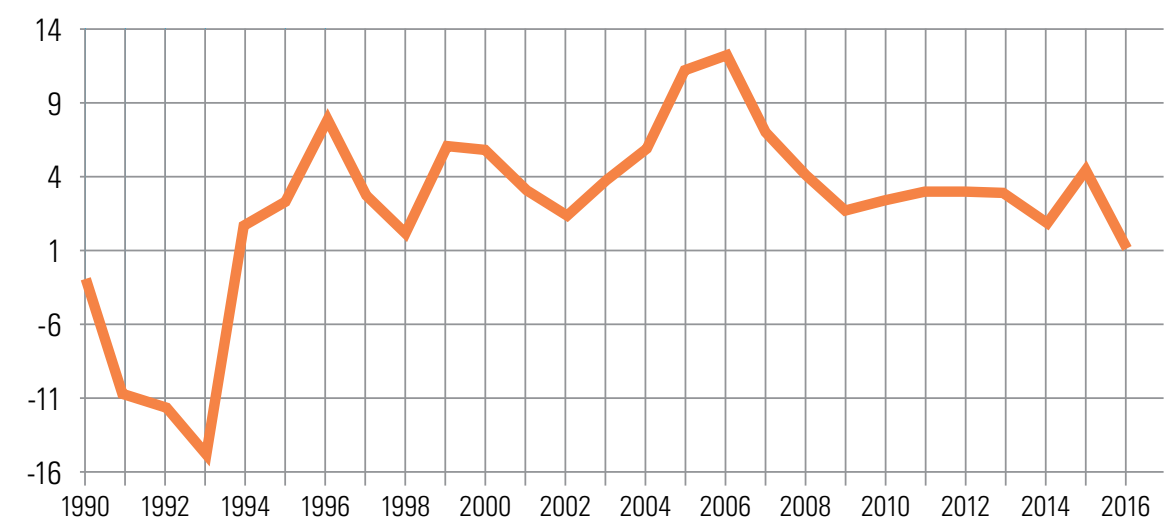

Fonte: Elaborado pelos autores com dados extraídos da CEPAL (2016).

Gráfico 2 - Déficit fiscal/PIB

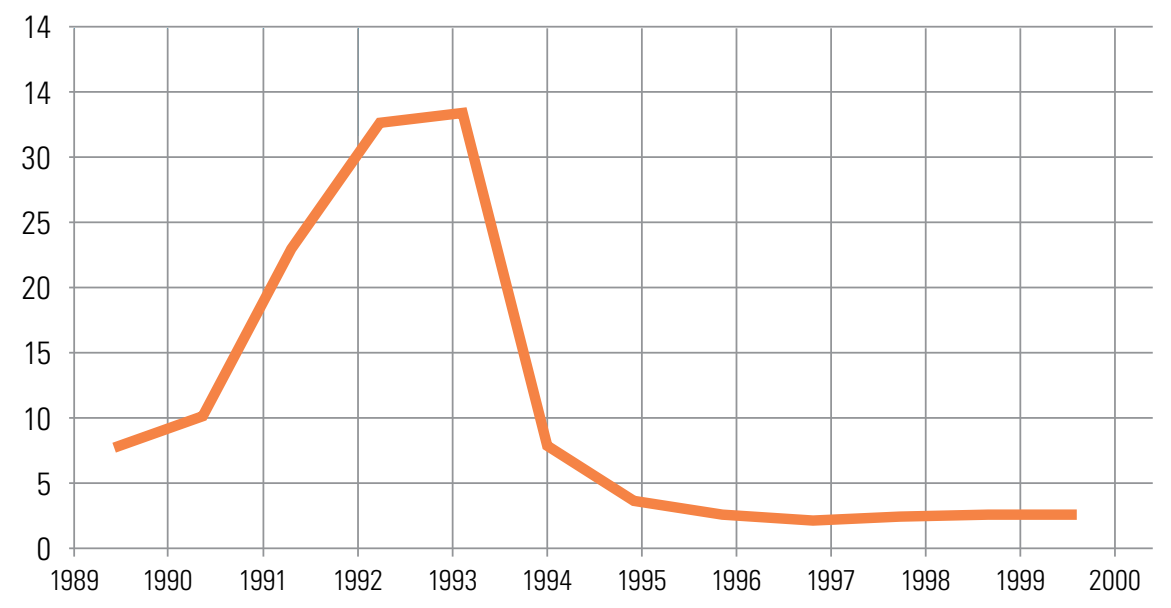

Fonte: Elaborado pelos autores com dados extraídos do Banco Central de Cuba (2000).
7. 0 emprego foi preservado, mas as custas do recrudescimento do processo inflacionário, como veremos na próxima seção. 
8. De acordo com Fidel Castro: "0 país sofreu um golpe devastador quando, de um dia para o outro, aquela potência desmoronou e nos deixou sozinhos, e perdemos todos os mercados do açúcar e deixamos de receber mantimentos, combustível e até madeira para fazer caixões para os nossos mortos. Ficamos sem combustível de um dia para o outro, sem matérias-primas, sem alimentos, sem higiene, sem nada" (RAMONET,

2006, p.332)

9. Em 1992 foi aprovada a Lei para Democracia em Cuba, conhecida como lei Torricelli. A Lei Torricelli estabeleceu sanções que visavam asfixiar o comércio cubano. Entre as principais medidas estavam a proibição do comércio entre

Cuba e empresas subsidiárias norte-americanas sediadas em outros países, e a proibição de navios comerciais de atracar em portos cubanos. Diante disso, os navios que desobedecessem ficariam proibidos de atracar em portos norte-americanos pelos próximos 180 dias (BCC, 2001). Em 1996, quando a economia cubana já tinha iniciado sua recuperação, foi aprovada a Lei para Liberdade e Solidariedade Democrática Cubana, conhecida como lei Helms-Burton, endurecendo ainda mais as medidas contra a economia cubana (DIÉGUEZ; GUZMÁN, 2014). Os mecanismos dessas leis aumentavam consideravelmente o risco país, o que, por sua vez, encarecia de forma exorbitante os custos para obter qualquer tipo de financiamento externo para suas operações comerciais (BCC, 2001).

10. Segundo Bandeira (2009), havia razões concretas para o governo cubano acreditar numa invasão dos Estados Unidos à llha. Apesar disso, em discursos, Fidel Castro admitiu que uma serie de erros relacionados a distribuição de alimentos, corrupção e o insucesso de regular os mercados na situaç̧ão em que o país estava.
Gráfico 3 - Comércio Externo (em milhões US\$)

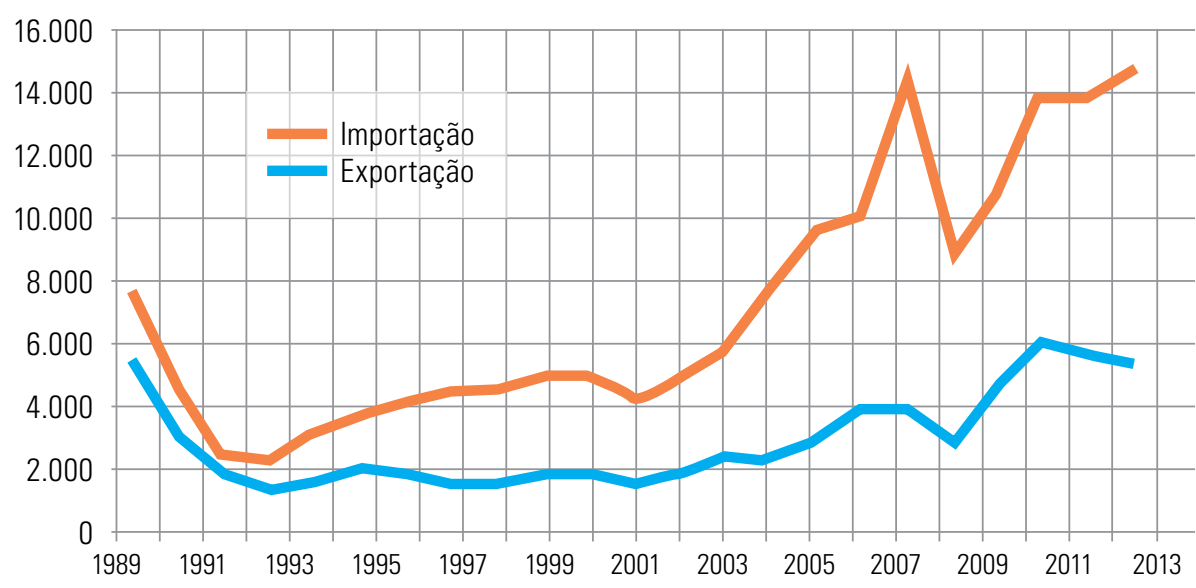

Fonte: Elaborado pelos autores com dados extraídos da ONEI-Cuba (2013).

No entanto, com o fim da URSS, a perda dos parceiros não se restringiu unicamente ao comércio. Na realidade ocorreu uma mudança profunda nas relações econômicas com o exterior e a interrupção de uma estratégia de desenvolvimento baseada nas relações preferenciais dentro dos países que formavam o COMECON. O fim da União Soviética e do COMECON colocaram em risco as conquistas sociais alcançadas a partir da vitória da revolução em 1959 e a própria manutenção de Cuba como nação soberana, dado o embargo do governo norte-americano sobre a Ilha. ${ }^{8}$

Por sua vez, a crise econômica tornou o país mais vulnerável à pressão dos Estados Unidos. As autoridades norte-americanas enxergaram nesse cenário uma oportunidade única para asfixiar a economia cubana, um intento buscado, então, há trinta anos. Com isso, ao mesmo tempo em que precisou estabelecer novas relações com os países capitalistas, Cuba teve que enfrentar o endurecimento das leis americanas contra a Ilha a fim de acelerar a queda do regime socialista, considerado uma questão de tempo para alguns analistas9 (GARCÍA, 2011).

Em agosto de 1990, as autoridades cubanas anunciaram um conjunto de resoluções que decretaram o Periodo Especial en Tiempos de Paz (CEPAL, 2000; BRITO, 2013; GARCÍA, 2013). Na prática, um plano de contingência concebido originalmente como uma resposta a condições de guerra ${ }^{10}$, que também incluía um conjunto de reformas econômicas a fim de modificar a estrutura da economia do país (CHANG, 2013; PÉREZ JR, 2006). Entre 1992 e 1998, o governo cubano executou um conjunto de medidas visando reestruturar e retomar o crescimento econômico. Conforme o BCC (2001), em relação ao setor externo as medidas foram: i) descentralização da atividade de comércio exterior, dando autorização a cerca de 350 empresas para importar e exportar, sendo antes do período especial, apenas 50 empresas; ii) autorização de funcionamento a 700 escritórios estrangeiros de representação comercial, sendo que o quadro de funcionários obrigatoriamente deveria conter cubanos, e todos os trabalhadores estrangeiros deveriam ser residentes; iii) abertura gradual aos investimentos estrangeiros, permitindo a criação de associações de capital misto, o que atraiu grande quantidade de divisas; iv) Ainda que não tenha liberalizado a conta financeira do balanço 
de pagamentos, autorizou o envio de remessas ao exterior sem restrição ${ }^{11}$; v) organização de três zonas francas e parques industriais; vi) aumento considerável das atividades turísticas que passaram a ser incentivadas vigorosamente pelo governo.

Em relação à política econômica, as reformas estruturais mais relevantes, na avaliação do BCC (2001) foram: i) reorganização da propriedade da terra - a propriedade da maior parte das áreas cultiváveis foi transferida às cooperativas e aos pequenos produtores; ii) ampliação das possibilidades de pequenos negócios autônomos como alternativa ao setor estatal; iii) criação de mercados agropecuários e de indústria artesanal por meio de comércio direto a preços não regulados; iv) reorganização dos organismos governamentais, com a redução do número de ministérios de 50 para 31; v) redimensionamento das empresas públicas, com concessão de maior autonomia em sua gestão; vi) substituição do planejamento material (em termos físicos) por um planejamento essencialmente financeiro; vii) programa de saneamento das finanças internas, que incluiu nova lei tributária; viii) despenalização da posse de divisas e facilidade na conversibilidade interna, ainda que, vale lembrar, seu uso como meio de pagamento e depósitos bancários não estivessem autorizados; ix) reorganização e modernização do Sistema Bancário e Financeiro Nacional (BCC, 2001).

Mais uma decisão a ser destacada, refere-se ao Decreto-Ley 141 que autorizou o trabalho por conta própria em alguns setores (BCC, 2001). A intenção era que tal atividade se tornasse um complemento à atividade estatal (CEPAL, 2000), mas como parte dessa forma de trabalho está vinculado ao setor de turismo, os trabalhadores por conta própria (os cuentapropistas, como são conhecidos) ganharam uma importância sobre o nível de atividade econômica considerável. ${ }^{12}$

Essas reformas, apesar de representarem uma abertura ao setor privado, não significaram uma adesão às reformas neoliberais experimentadas por outros países da América Latina. O movimento de reformas em Cuba incorporou decisões deliberadas de distribuição equitativa dos encargos decorrentes da mudança de estratégia para enfrentar a conjuntura adversa (CEPAL, 2000; FABIENKE, 2001). Isso tudo com o objetivo de manter os direitos sociais e os objetivos fundamentais do projeto socialista cubano.

De tal modo, após quatro anos de profunda recessão, no fim de 1994, as reformas apresentaram alguns resultados satisfatórios. Especialmente pelo desenvolvimento do setor de turismo pelo qual ocorre o ingresso direto de divisas - em 2016, havia 27 empresas mistas e 76 contratos de associação econômica ${ }^{13}$ de 17 grupos estrangeiros neste setor (DESSOTTI 2017), além do efeito multiplicador sobre a atividade econômica em outros setores da economia. Também houve uma forte entrada de capitais estrangeiros europeus e canadenses em joint ventures.

A economia cubana voltou a crescer e o déficit fiscal em 1995 já estava em 3,5\%, mantendo-se em torno de $2,5 \%$ nos anos seguintes. Isso ajudou a reduzir o excesso de liquidez da economia. Tanto as exportações quanto as importações se recuperaram. A taxa de câmbio no mercado paralelo, que alcançou aproximadamente 150 pesos por dólar, se estabilizou em torno de 20 pesos por dólar a partir de 1996, e depois como veremos
11. Cumpre ressaltar que a livre circulação de moeda estrangeira no país continuava proibida. Somente as entidades autorizadas a operar com comércio e investimentos estrangeiros tinham acesso a divisas. 0 uso do CUC demonstra que o governo cubano não pretendeu perder o controle sobre a política monetária.

12. Segundo Anuário Estadístico de Cuba (2017), existem atualmente 540,8 mil pessoas trabalhando por conta própria. Desses, 174,8 são mulheres. Isso representa cerca de $12 \%$ dos trabaIhadores ocupados no país. Cf. também Meneses (2017).

13. Conforme a autora, não há criação de uma personalidade jurídica, mas o acordo entre uma empresa estatal cubana e uma empresa estrangeira. A Lei 118 de 2014 determina que classificam-se, entre outros, os contratos de risco de exploração de recursos naturais não renováveis, para a construção, a produção agrícola, a administração hoteleira, produtiva ou de serviços e os contratos para prestação de serviços profissionais". 
A recuperação da economia é também decorrência da resposta singular e bem-sucedida que as autoridades cubanas deram ao processo de dolarização, conforme discutiremos na próxima seção.

A dolarização parcial durante o período especial

A dolarização parcial da economia cubana tem origem nos graves desequilíbrios macroeconômicos decorrentes do choque externo analisado na seção anterior. $O$ governo decidiu que o ajuste deveria ser o mais simétrico possível, impedindo que seus impactos recaíssem exclusivamente sobre determinados setores (ALEJANDRO, 2008; MORRIS, 2014). Assim, o governo buscou manter o emprego dos trabalhadores, apesar da queda acentuada da produção doméstica. Como o setor público é o maior empregador em Cuba, a manutenção do emprego levou ao aumento do subsídio dado às empresas estatais. Entre 1989 e 1993, os subsídios associados aos prejuízos dessas empresas cresceram a um ritmo médio de $15,1 \%$ ao ano em termos reais. Em 1993, os subsídios representaram 33\% do PIB (CEPAL, 2000). Ademais, a manutenção em termos nominais dos gastos sociais (saúde, educação subsídios aos alimentos e assistência social) provocou um aumento da emissão monetária que não tinha contrapartida com a oferta de mercadorias e serviços. Isso se traduziu em uma acumulação de pesos dentro e fora do sistema bancário (tabela 2). Entre 1990 e 1993, os saldos monetários nas mãos da população (circulante mais poupança) aumentaram a um ritmo anual de $23 \%$ em termos reais (CEPAL, 2000).

Tabela 1 - Liquidez nas mãos da população (em milhões de CUP)

\begin{tabular}{c|c|c|c}
\hline & Oferta Monetária & Circulação Efetiva & Poupança \\
\hline 1990 & $4,986.30$ & $2,341.20$ & $2,645.10$ \\
\hline 1991 & $6,562.90$ & $3,317.40$ & $3,245.50$ \\
\hline 1992 & $8,361.10$ & $4,081.50$ & $4,279.60$ \\
\hline 1993 & $11,043.30$ & $4,554.60$ & $6,488.70$ \\
\hline 1994 & $9,943.80$ & $3,601.50$ & $6,342.30$ \\
\hline 1995 & $9,251.20$ & $3,547.00$ & $5,704.20$ \\
\hline 1996 & $9,534.30$ & $3,981.10$ & $5,553.20$ \\
\hline 1997 & $9,441.10$ & $4,014.00$ & $5,427.10$ \\
\hline 1998 & $9,710.00$ & $4,282.70$ & $5,427.30$ \\
\hline 1999 & $9,902.20$ & $4,568.00$ & $5,334.20$ \\
\hline 2000 & $10,489.80$ & $5,054.80$ & $5,435.00$ \\
\hline
\end{tabular}

Fonte: Banco Central de Cuba

Nessas condições a monetização do déficit público era inevitável,

14. Cuba já tinha dificuldades consideráveis em conseguir financiamento externo por efeito da moratória unilateral da dívida externa anunciada em julho de 1986. uma vez que o país praticamente não tinha acesso a financiamento externo ${ }^{14}$, e não contava com um mercado de dívida pública que possibilitasse seu financiamento que é característico das economias planificadas. O processo inflacionário daí decorrente promoveu um processo gradual de substituição do peso, não somente em sua função de reserva de valor, mas também como meio de troca (HIDALGO; REYES, 2003; ALEJANDRO; VILLANUEVA, 2013). 
A substituição da moeda nacional foi alimentada pela ação dos especuladores e pela criação de um mercado paralelo de produtos e divisas. O uso do dólar, mesmo sendo ilegal, passou a se disseminar entre a população e o peso entrou num processo de desvalorização contínua no mercado paralelo. Isso foi facilitado com o aumento do fluxo de dólares advindos das remessas de famílias cubanas que vivem nos Estados Unidos e que o governo passou a incentivar, e do turismo que estava se tornando a principal atividade econômica (BCC, 2001). Logo, as condições materiais para o processo de dolarização estavam colocadas. Mas o caso cubano é singular, dado que a dolarização não foi precedida por um aumento descontrolado no índice de preços no mercado formal, como ocorreu em outras experiências (CEPAL, 2000).

Tabela 2 -Cuba: Índices de Preços, 1989-1998 (1989=100.0)

\begin{tabular}{c|c|c|c|c|c|c|c}
\hline & 1889 & 1993 & 1994 & 1995 & 1996 & 1997 & 1998 \\
\hline Deflator do PIB $^{\mathrm{a}}$ & 100,0 & 116,9 & 142,4 & 157,0 & 155,1 & 152,5 & $158,5^{\mathrm{b}}$ \\
\hline Mercado Informal $^{\mathrm{c}}$ & 100,0 & 552,6 & 396,5 & 739,6 & 554,7 & n.d. & n.d. \\
\hline
\end{tabular}

Fonte: CEPAL (2000)

a-Sobre a base dos preços de 1981; b-Estimativas;

c- Sobre a base de una cesta de 91 produtos; n.d-Não Disponível

Isso somente ocorreu porque devido à condição socialista do Estado cubano, havia um monitoramento dos preços relativamente eficiente por parte das autoridades, fazendo com que os desequilíbrios fossem observados primeiramente na escassez de produtos básicos, como alimentos, produtos de higiene, vestuário e remédios. Tais desequilíbrios foram se acentuando à medida que governo continuava financiando o crescente déficit público com emissão monetária (HIDALGO; REYES, 2003). Existia, portanto, uma inflação reprimida, mas só quando o mercado paralelo ganhou vulto, é que os preços e o câmbio começaram a refletir os desequilíbrios monetários.

Tabela 3 - Cuba: Cotações Paralelas do Tipo de Câmbio, 1989 -1998 (Pesos por Dólar - Media Anual)

\begin{tabular}{c|c|c|c|c|c|c|c|c|c|c}
\hline & 1889 & 1990 & 1991 & 1992 & 1993 & 1994 & 1995 & 1996 & 1997 & 1998 \\
\hline Resto do Mundo & 45 & 68 & 120 & 150 & 137 & 68 & $\ldots$ & $\ldots$ & $\ldots$ & $\ldots$ \\
\hline Em Cuba & 5 & 7 & 20 & 45 & 100 & 60 & 25 & 19 & 22 & 21 \\
\hline
\end{tabular}

Fonte: CEPAL (2000)

Como resposta, o governo cubano iniciou uma reforma financeira que ampliou e diversificou o sistema financeiro cubano. Em agosto de 1993, o governo decidiu legalizar a posse e o uso do dólar para transações por meio do Decreto-Ley $140^{15}$. (BCC, 2001). Cuba precisava se reinserir na economia mundial a fim de reduzir sua restrição externa para superar a crise. Nesse sentido, a legalização da circulação do dólar ajudou a reduzir as pressões inflacionárias ao elevar a capacidade de importação do país, estimulando a recuperação da produção (CEPAL, 2000, p.55). Na avaliação de Hidalgo; Reyes (2003, p.55), as autoridades cubanas instituí-
15. Mesa-Lago (1994, p.378) descreve que: "La bomba explotó a fines de junio, cuando Castro señaló a la Asamblea Nacional que el proceso de dolarización era una realidad debido a la situación económica y a La insuficiencia de policías para hacer cumplir la ley, y que en consecuencia, había llegado el momento de cambiar". 
16. Disponível em: <Cf. http://www. bc.gob.cu/Espanol/sist_bancario.asp.> Acesso em: 02 jul.2018.

17. 0 Banco Nacional de Cuba se desligou das incumbências de Banco Central para especializar-se na gestão da dívida externa e em operações de apoio a relações econômicas externas.

18. Esse é o caso de Mariel. Uma Zona Econômica de Desenvolvimento (ZED), inaugurada em janeiro de 2014, via decreto lei 313. Há tratamento especial para as empresas estabelecidas em Mariel dado o seu objetivo de promover a infraestrutura para estimular exportações, a substituiç̧ão de importações, bem como induzir projetos voltados para inovação tecnológica. É uma área industrial com um porto que pode receber embarcações de grande porte. Dessoti (2017) esclarece que o governo cubano tem se esforçado para atrair empresas de biotecnologia, farmacêutica, informática, além da infraestrutura, totalizando, conforme a carteira de oportunidade de investimentos 2016-2017, 24 oportunidades de investimento na ZED Mariel, o que representa $5 \%$ do total. A autora aponta que dos 22 projetos instalados, 8 estavam em operação em 2017. ram, na prática, uma reforma monetária parcial equivalente a uma substituição da moeda nacional em um setor da economia.

Foram criadas as Tiendas de Recuperación de Divisas, no qual são vendidas mercadorias em moeda estrangeira com o objetivo de arrecadar divisas para fins redistributivos (MOLINA, 2005, p.16). O Banco Popular de Ahorro (BPA) fundado em 1983 - o primeiro criado após a revolução e atualmente presente em quase todos os municípios cubanos - foi autorizado a abrir contas em moeda estrangeira com taxas de juros mais atrativas, o que propiciou um fluxo crescente de recursos.

Some-se a isso, a modernização e formação, durante os anos 1990, de bancos e instituições financeiras especializadas em servir à reconstrução do comércio exterior cubano. Foram criados os seguintes bancos comerciais: Banco de Inversiones S.A, Banco Metropolitano S.A, Banco Internacional de Comercio S.A, Banco de Crédito y Comercio, Banco Exterior de Cubae, já em 2005, o Banco Industrial de Venezuela-Cuba S. A.E mais 14 instituições financeiras não bancárias entre os anos 1990 e 2000. Entre elas: Grupo Financiero Nueva Banca, Casas de Cambio, S.A. (CADECA), e a Corporación Financiera Habana. Também se criou a oportunidade para participação de bancos estrangeiros. O BCC informa que há nove bancos estrangeiros operando em Cuba, como Havin Bank Ltda da Inglaterra, e mais três instituições financeiras não bancárias, como a Nova fin Financiere S.A da Suíça ${ }^{16}$.

Vale destacar, o Decreto $\mathrm{n}^{\circ} 172$ criou o Banco Central com autoridade supervisora, reguladora e servindo como emprestador de última instância do sistema financeiro cubano constituído atualmente por nove bancos comerciais, incluído o Banco Nacional de $\mathrm{Cuba}^{17}$ que fazia, até então, o papel de banco central e quatorze instituições financeiras não bancárias, além das instituições estrangeiras.

O marco desse processo foi a criação da CADECA, em junho de 1994. Essa instituição realiza transações de pesos cubanos por divisas, negociam cheques, operações com cartões de crédito e serviços vinculados com moeda estrangeira. Qualquer cidadão cubano pode vender e comprar divisas. A CADECA se transformou em referência para a gestão da política monetária. O BCC realiza intervenções, indicando a taxa de câmbio para população e para os turistas estrangeiros (MOLINA, 2005; HIDALGO, 2013). A CADECA foi fundamental ainda para o reconhecimento das condições de oferta e demanda por dólares. Em pouco tempo a taxa de câmbio se estabilizou se tornando referência fundamental para a gestão da política monetária do BCC (HIDALGO, 2013). Desse modo, além da legalização da circulação dos dólares, foi criado um mercado estatal interno de divisas e um circuito empresarial vinculado ao turismo e ao investimento externo direto (IED) ${ }^{18}$ no qual todas as transações são realizadas em moeda estrangeira (HIDALGO, 2013).

Em fins de 1994, o governo anunciou a criação do peso cubano conversível (Resolución $\mathrm{n}^{\circ}$ 357), o CUC - ou "chavito" como popularmente passou a ser conhecido no país - desempenhando todas as funções da moeda. A ideia era criar uma moeda que fosse "as good as dollar", a fim de estabilizar a taxa de câmbio e reduzir a dolarização. O dólar e outras moedas conversíveis podiam circular, mas o propósito era retirar essas moedas de circulação, redirecionando-as para propósitos sociais. A taxa 
de câmbio da nova moeda com o dólar foi estabelecida em 1 CUC igual a 1 USD. Ademais, criou uma caixa de conversão que respaldou a paridade com o dólar que durou até 2003. Neste momento, não existem regras de emissão do CUC (ALEJANDRO; VILLANUEVA, 2016).

O sistema passou a conviver com duas taxas de câmbio oficiais. Atualmente, o peso cubano e o peso conversível seguem com uma taxa de câmbio fixa de 1 US\$ por 24 CUPs e 1 CUC por 25 CUPs nas CADECAs. No entanto, para as empresas estatais e organizações públicas, além de empresas estrangeiras e empresas mistas ${ }^{19}$, a taxa de câmbio permanece em 1 CUP por 1 US\$ (e 1 CUP por 1 CUC.), a mesma dos anos 1980. Portanto, para os registros das contas nacionais e das finanças das empresas a taxa de câmbio também segue sendo de 1 CUP igual a 1 US\$. As empresas são proibidas de arbitrar com a taxa de câmbio nas CADECAs (ALEJANDRO; VILLANUEVA, 2013; TORRE; IZE, 2014).

Inicialmente, o CUC teve uma circulação muito restrita como meio de pagamento nos mercados de varejo, e em certas condições de forma apenas virtual ${ }^{20}$, mas gradualmente tornou-se a principal moeda conversível em circulação, sendo que a partir de 2001 seu uso passou a ser generalizado (GARCÍA, 2013). Desse modo, a introdução paulatina do CUC em conjunto com a redução dos dólares em poder do público, fortaleceu a política monetária cubana. As autoridades monetárias passaram a ter um controle mais efetivo sobre a circulação de dinheiro, dado que o valor dos dólares em poder do público não está nos registros dos agregados monetários (MOLINA, 2005; ALEJANDRO, 2004).

A decisão de legalizar o uso do dólar e a criação do CUC impulsionaram o IED em Cuba, que também passou a ser incentivado por meio da Ley 77 de 1995 (Nueva Ley de Inversión Estranjera) que autoriza a propriedade total do investimento em mãos de empresas estrangeiras. A lei também garante que os investidores em Cuba sejam protegidos da expropriação, exceto em casos de "utilidade pública ou interesse social"(CUBA, 1995). Nos seus primeiros anos, o IED foi atraído para exploração de novos depósitos de níquel e cobalto. Depois se expandiu para várias áreas, incluindo o setor imobiliário e financeiro (BCC, 2001).

As novas condições gestadas pelas reformas permitiram aos setores mais dinâmicos da economia cubana - como o turismo ${ }^{21}$ e a biotecnologia - ensaiar uma recuperação da produção por meio de um manejo mais eficiente das divisas disponíveis. Ao mesmo tempo em que parte das divisas que entravam no país era agora recolhida pelo governo cubano.

A (re) centralização do sistema e a desdolarização

A recuperação da economia a partir de 1995 conseguiu restaurar, em alguma medida, a credibilidade de Cuba no mercado internacional. Em 1999 e 2000, o país já tinha algumas facilidades de crédito externo de médio e longo prazo. Todavia, depois do ataque terrorista de 11/09 de 2001 nos Estados Unidos, houve uma queda acentuada na entrada de capitais, em particular no setor de turismo, o que criou novas tensões financeiras. O governo norte-americano também decidiu apertar, ainda mais, o bloqueio econômico ao fazer valer as leis Torricelli e Helms-Burton ${ }^{22}$. E, no
19. Empresas com participação do capital estrangeiro e do capital nacional Em Cuba é a nacionalidade do capital que importa nesta definição e não 0 seu tipo, se público ou privado. É uma empresa cubana, com acionistas uma ou mais empresas estatais cubanas e um ou mais investidores estrangeiros. Via o capital social formado com 0 aporte de sócios, o seu objetivo é a obtenção de lucro e é a modalidade de IED mais usada em Cuba (DESSOTTI, 2017).

20. Os salários dos trabalhadores cubanos das empresas estrangeiras são denominados em CUCs, porém recebem em CUPs. Inicialmente a taxa de câmbio era de 1 CUC igual a 1 CUP. Desde 2014 a taxa de câmbio para esses trabalhadores é de 1 CUC igual a 2 CUPs.

21. “Em 2015 chegaram ao país 3.524.779 visitantes, representando um aumento de $17,4 \%$ em relação ao ano anterior" (PÉRICAS, 2017). 
âmbito da economia doméstica, a partir de 2003, muitas empresas, cujos produtos eram transacionados em moeda conversível não estavam agindo com a disciplina financeira exigida para aliviar o país da escassez de divisas vinculadas à produção doméstica e aos programas sociais (GARCÍA, 2013).

A resposta das autoridades cubanas a esses desafios foi uma série de novas regulamentações anunciadas em julho de 2003, provocando uma transformação no sistema monetário que descrevemos anteriormente, e tornando-o mais centralizado (MESA-LAGO, 2005). Essas medidas buscavam restringir o uso do dólar e ampliar o uso do CUC, num processo de desdolarização. Por meio da Resolução $\mathrm{n}^{\circ}$ 65, de julho de 2003, estabeleceu-se o uso do CUP e CUC como meios de pagamento para denominar e executar as transações entre as entidades estatais cubanas incluindo os créditos e outros financiamentos que estas recebem (ALEJANDRO, 2008).

O Banco Central assumiu o controle das negociações com moeda estrangeira, reduzindo drasticamente as empresas que podiam operar com moeda conversível. Em vez das operações cambiais serem automáticas, as empresas que precisavam comprar insumos no mercado externo deviam apresentar requerimento ao BCC. Essa instituição analisava e priorizava de acordo com as necessidades gerais da economia cubana, ainda que as regras para rejeição ou aprovação dos pedidos não estivessem claros (MESA-LAGO, 2005). Com isso, avalia García (2013), o BCC pôde reduzir a tensão que pairava no mercado cambial.

Em novembro de 2004, a Resolução ${ }^{\circ} 80$ ampliou a utilização do CUC. A circulação do dólar foi novamente proibida no comércio varejista. A venda de dólares passou a ter uma sobretaxa de $10 \%$, e as operações bancárias das empresas que fazem negócios no exterior foram convertidas de dólares para CUCs (ALEJANDRO; VILLANUEVA, 2013; MESA-LAGO, 2005; CEPAL, 2006). A Resolução $n^{\circ} 80$ estabeleceu ainda que o pagamento de serviços pela população e turistas estrangeiros, anteriormente realizadas em dólar, seria em pesos conversíveis. Logo, o CUC tornou-se a única moeda permitida na rede de lojas autorizadas a utilizar moeda conversível. Desse modo, as empresas foram obrigadas a trocar moeda conversível por CUCs para realizar transações.

Some-se a isso, a Resolução no 92, de 29 de dezembro de 2004 que fez com que as transações em moedas estrangeiras ficassem quase totalmente centralizadas em uma única conta no Banco Central denominada de "Cuenta única de ingresos en divisas del Estado" (GARCÍA, 2013; CHANG, 2013, p.101; MOLINA, 2005). Dessa forma, o governo desestimulava a entrada de dólares no sistema financeiro cubano, facilitando a administração da política monetária na medda que a oferta monetária ficou restrita a duas moedas domésticas (ALEJANDRO, 2004; CEPAL, 2006; HIDALGO, 2008).

$\mathrm{Na}$ avaliação de Alejandro (2004), as medidas ajudaram a desenvolver o sistema financeiro cubano. Houve um aumento da demanda por serviços bancários pela população, como a abertura de contas correntes em pesos conversíveis, assim como a utilização dos bancos para o recebimento de dinheiro do exterior. A população também teria ficado mais atenta às questões financeiras, como juros e taxa de câmbio. Os bancos saíram mais fortalecidos em razão do aumento dos depósitos e dos ganhos com o aumento dos serviços bancários. 
Por sua vez, cresceu o estoque de reservas internacionais em poder do BCC, propiciando uma maior segurança ao sistema financeiro, o que contribuiu para o acesso aos mercados financeiros internacionais. Além disso, fatores não meramente econômicos tiveram peso para reduzir a restrição externa, como a renegociação da dívida externa no começo dos anos 2000 e novos acordos comerciais vantajos com Venezuela e a China. (GUTIÉRREZ, 2017; HIDALGO, 2008; CEPAL, 2006). Todavia, segundo explicação de Alejandro e Villanueva (2013), até então a emissão de CUCs estava ancorada na entrada de divisas, em um esquema semelhante ao currency board. Após as medidas adotadas esse controle foi eliminado sem que uma nova uma regra fosse introduzida, provocando um aumento do estoque de CUC sem contrapartida em divisas. Segundo Ugarte (2014) para contrabalancear esse problema, foi criada uma terceira "moeda", a Carta de Liquidez (CLC), com a qual se identificam os CUCs que tem respaldo e podem ser trocados por divisas ${ }^{23}$.

É importante destacar que essas reformas coincidiram com a melhora no cenário externo para as economias da América Latina e Caribe, como um todo. Nesse período, ocorreu um aumento nos preços das commodities, criando condições mais favoráveis para os países da região quanto à administração do balanço de pagamentos. Ademais, uma série de governos críticos à agenda neoliberal colocada em prática principalmente durante a década de 1990 ascendeu, pela via eleitoral e num curto espaço de tempo, à presidência da república. Esses governos modificaram a fisionomia política e econômica da região, favorecendo Cuba. No plano externo houve uma retomada de projetos antigos de integração (Mercado Comum do Sul - MERCOSUL e a Associação Latino-Americana de Integração - ALADI), e projetos novos foram sendo construídos, como a Aliança Bolivariana para os Povos da Nossa América -ALBA), em que Cuba foi inserido numa parceria com a Venezuela (FIORI, 2013). A aproximação com a Venezuela significou um alívio em relação à oferta de energia, um dos problemas crônicos de Cuba.

Entretanto, a dualidade monetária e a dualidade da taxa de câmbio na prática criaram dois segmentos na economia cubana: uma ligada eminentemente ao setor estatal que negocia com CUP e outra ao setor privado que negocia em CUCs. Com isso, criaram-se graves distorções na contabilidade das empresas. Houve um aumento dos custos de transação relacionados à conversão das moedas, e a taxa de câmbio fixa sobrevalorizada reduziu a competitividade do comércio cubano. O sistema é também um complicador para empresas estrangeiras que precisam comprar insumos locais, o que torna caro produzir em Cuba. Por outro lado, o câmbio valorizado é vantajoso para as empresas com alta proporção de insumos importados, configurando-se em subsídios disfarçados que não aparecem nas contas públicas e ocultam a real situação financeira da empresa (MESA-LAGO, 2013; HIDALGO, 2013). Isto dificulta às decisões sobre a alocação de recursos e o reconhecimento do grau de competitividade das suas indústrias e de cada mercadoria produzida, gerando custos consideráveis, principalmente ao setor público cubano que detém o maior peso na economia.

Além disso, geraram-se distorções sociais graves relacionadas ao consumo de mercadorias, entre aqueles com acesso e sem acesso à moe-
23. Infelizmente não há maiores informações sobre a CLC no sítio do Banco Central de Cuba (BCC). Vale destacar que Ugarte (2014) é assessor da presidência da Asociación Nacional de Economistas y Contadores de Cuba. 
24. Vale lembrar que a estrutura de serviços públicos se mantêm universal. Portanto, parte considerável da subsistência da população cubana não passa diretamente pelo mercado. Uma especificidade da economia socialista cubana. da estrangeira e ao peso conversível. Desde as reformas dos anos 1990, a quantidade de mercadorias que são compradas e vendidas a preços próximos aos preços do mercado internacional vem aumentando (HIDALGO, 2008). O privilégio daqueles que obtêm dólares ou CUCs - os trabalhadores do setor de turismo e os trabalhadores por conta própria que trabalham exclusivamente com CUCs - provocou um retrocesso na igualdade social, deteriorando o nível de vida dos chamados "grupos de risco" na sociedade, isto é, aqueles que não têm acesso às remessas estrangeiras ou que de alguma maneira foram afetados pelas reformas (MESA-LAGO, 2002; HIDALGO, 2008).

Dessa forma, os ganhos advindos da atividade informal e dos pequenos empreendimentos privados passaram a ter uma importância que até então não tinham. Criou-se uma situação paradoxal em que professores universitários, entre outros servidores públicos, ganham menos que taxistas e guias turísticos, o que tem levado a uma espécie de "domestic brain drain" (CHOMSKY, 2015). Isto também tem levado ao aumento de serviços ilegais, como a prostituição ligada ao turismo, setor que é a principal fonte de renda em CUCs. O problema fica visível quando são comparados os salários. Mesa-Lago (2013) aponta que, em 2012 o salário médio mensal no setor estatal era 460 CUPs, menos de US\$ 20 mensais. Um proprietário de restaurante Paladar com 50 lugares, que negocia em CUCs, pode faturar até US\$20 mil ao mês, ou seja, mil vezes mais. Isso numa sociedade em que a igualdade social está muito arraigada entre os valores conquistados pela revolução ${ }^{24}$

Os graves problemas econômicos e sociais oriundos do atual sistema geraram nas autoridades cubanas a percepção da urgência de uma nova reforma que elimine a dualidade monetária e cambial. Nessa perspectiva, em 2011, o VI Congresso do PCC aprovou que o sistema deverá ser encerrado, mas sem apontar uma data definida para o chamado "dia zero", quando o CUC seria abolido. Em outubro de 2013, em um comunicado, o governo anunciou que começaria o processo de unificação das duas moedas. E, em documento recente do PCC (2017) que trata da política econômica e social do governo para os próximos anos mais uma vez foi ratificada a importância da unificação monetária e cambial. No entanto, não foram dadas maiores explicações sobre quando e como ocorrerá o fim do sistema dual, além de garantias que os investidores e a poupança da população em geral não seriam afetados. Por certo as autoridades cubanas avaliam que a os riscos associados ao fim da dualidade são muito consideráveis. Entre os riscos, entendemos que o principal reside justamente em que nível a taxa de câmbio irá se estabilizar quando ocorrer a unificação monetária dado que a taxa de câmbio dual também será abolida.

A incerteza sobre a nova taxa de câmbio traz ameaças à estabilidade dos preços, ao investidor estrangeiro e àquelas empresas muito dependentes de insumos importados. Isso está relacionado ao excesso de CUCs em mãos do setor não estatal em relação às reservas internacionais. As instituições com excesso de liquidez serão levadas a demandarem divisas forçando uma desvalorização que poderá sair do controle do Banco Central. Embora não existam dados disponíveis em relação à quantidade de 
pesos conversíveis, a própria emissão de uma "terceira moeda", a CLC, demonstra que o problema existe.

Considerações finais

A criação do CUC se mostrou uma medida criativa que alcançou com relativo sucesso seu objetivo de substituir o dólar numa economia que, no início dos anos 1990, por conta de um violento choque externo passava por um processo crescente de dolarização. Vale destacar que, a resposta sui generis das autoridades cubanas tornou-se ainda mais impressionante quando se leva em conta que Cuba ainda é um país com um sistema financeiro pouco desenvolvido, aquém das necessidades de sua economia planificada, o que torna qualquer plano na área monetária um desafio considerável.

As medidas adotadas aqueceram a atividade produtiva, reanimaram o comércio exterior e criaram uma nova fonte de divisas, sobretudo por meio do turismo. Isso permitiu que se evitasse a adoção de um ajuste macroeconômico recessivo com todas as consequências negativas sobre a população que tal ajuste normalmente carrega. Embora com restrições materiais visíveis, o país logrou manter a estrutura de serviços públicos, notadamente nos setores de saúde e educação. Todavia, existe uma concordância de que a manutenção do sistema não é possível por muito mais tempo, em razão das distorções econômicas e sociais advindas da dualidade, e pelas reformas gerais que a economia cubana precisa colocar em movimento para manutenção do sistema socialista numa conjuntura econômica internacional desfavorável. A unificação monetária e cambial evidentemente não resolveria todos os problemas econômicos, mas é imprescindível para o sucesso das reformas que o país implementou nos últimos anos.

Portanto, a singularidade do sistema monetário cubano já teria cumprido sua função histórica. A questão está em realizar a unificação monetária sem recriar os problemas enfrentados pelo país nos anos 1990, em particular aqueles relacionados aos movimentos especulativos contra o peso, ainda que o realinhamento cambial seja inevitável. Isso num cenário externo hostil, uma vez que persiste o bloqueio econômico norte-americano em que pese o esforço de reaproximação dos dois países.

Referências

ALEJANDRO, Pavel Vidal. Implicaciones de la circulación del peso convertible para la política monetária. Revista del Banco Central de Cuba. Año7, nº 4. Edición Especial, 2004.

ALEJANDRO, Pavel Vidal; Omar Everleny Pérez,VILLANUEVA. La reforma monetaria en Cuba hasta el 2016: entre gradualidady 'big bang', Centro de Estudios de la Economía Cubana, Universidad de la Habana, 2013. Disponível em: http://www.brookings.edu/es/research/ papers/2014/01/monetary-reform-cuba-2016-radualism-big-bang-alejandro-villanueva $>$. Acesso em: abril de 2015.

ALEJANDRO, Pavel Vidal. Los Salarios, los Precios, y la Dualidad Monetaria, Espacio Laical 2: $22-6,2008$.

Anuario Estadístico de Cuba 2016. Empleo y Salarios. Oficina Nacional de Estadísticas y Información. Disponível em: <http://www.one.cu/aec2016/07\%20Empleo\%20y\%20Salarios.pdf >. Acesso em: 02 jul. 2018. 
BANCO CENTRAL DE CUBA (BCC). La Economia Cubana En El Período Especial 1990-2000, 2001. Disponível em: $<$ http://www.bc.gob.cu/Anteriores/Otros/economia\%20cubana.pdf $>$. Acesso em: 02.jul.2018.

BANDEIRA, Luiz Alberto Muniz. De Martí a Fidel: a Revolução Cubana e a América Latina. Rio de Janeiro: Civilização Brasileira, 2009.

BRITO, Julian Araujo. "Pátria ou morte": crise e sobrevivência do regime revolucionário cubano nos anos 90. Revista Eletrônica da ANPHLAC, n.14, p. 287-315, jan./jun. 2013. Disponível em: <http://revistas.fflch.usp.br/anphlac/article/view/1238>. Acesso em: 02 jul.2018.

CEPAL. Cuba: Evolución Económica Durante 2005 y perspectivas para 2006. Naciones Unidas Comisión Económica para América Latina y el Caribe - CEPAL. 13 set. 2006.

CEPAL. La Economía Cubana. Reformas estructurales y desempeño em los noventa. México: CEPAL, Fondo de Cultura Económica, 2000.

CEPAL. Balance preliminar de lãs economias de América Latina y el Caribe, 2009.

CHANG, Nancy A. "Quiñones Cuba's Insertion in the International Economy since 1990”. CAMPBELL, Al (ed) In: Cuban Economists on the Cuban Economy. University Press of Florida, 2013.

CHOMSKY, Aviva. A History of the Cuban Revolution. $2^{\circ}$ ed. John Wiley\& Sons, Inc, 2015.

CUBA. Ley 77 (1995) para la inversión extranjera. Cuba Industria, 16 nov. 2015 (1995). Disponível em: <http://www. cubaindustria.cu/index.php/comercio-exterior/inversiones-extranjeras>. Acesso em: 02 jul. 2018.

DESSOTTI, Fabiana Rita. Quais as regras para o capital estrangeiro em Cuba? IN: SANTOS, Fabio Luis Barbosa dos; VASCONCELOS, Joana Salém; DESSOTTI, Fabiana Rita. Cuba no século XXI: dilemas da revolução. São Paulo: Elefante, 140-151. 2017.

DIÉGUEZ, Andrés Zaldívare; GUZMÁN, Gretter Alfonso. La persecución financiera contra Cuba (segunda parte) 1981-2000: las presiones contra Cuba se recrudecen, Granma, 17 de outubro de 2014. Disponível em: http://www.granma.cu/cuba/2014-10-17/la-persecucion-financiera-contra-cuba-segunda-parte-1981-2000-las-presiones-contra-cuba-se-recrudecen $>$. Acesso em: 02 jul.2018.

FABIENKE, Rikke. Labour Markets and Income Distribution during Crisis and Reform. In: BRUNDENIUS, Claes e WEEKS, John. Globalization and Third World Socialism: Cuba and Vietnam. New York: Palgrave, 2001.

FERRER, Lissett Izquierdo. Se alista el Banco Central para La unificación monetária. Granma, 30 de setembro. Disponível em: <http://www.granma.cu/cuba/2014-09-30/se-alista-el-banco-central-para-la-unificacion-monetaria >. Acesso em: 02 jul.2018.

FIORI, José Luís (2013). O Brasil e seu "entorno estratégico" na primeira década do século XXI. In: SADER, Emir (2013). 10 anos de governos pós-neoliberais no Brasil: Lula e Dilma. São Paulo: Boitempo.

GARCÍA, José Luis Rodríguez. A economia cubana: experiências e perspectivas (1989-2010). Estudos avançados, vol. 25 n.72, 2011.

GARCÍA, José Luis Rodríguez. Fifty Years of Revolution in the Cuban Economy: A Brief Overview. CAMPBELL, Al (ed) In: Cuban Economists on the Cuban Economy. University Press of Florida, 2013.

GARCÍA, José Luis Rodríguez. Presentación a la Asamblea Nacional del Poder Popular del informe sobre los resultados económicos del 2008 y los Lineamientos del Plan Económico y Social para el 2009. Juventud Rebelde: Diario de La juventud cubana, 2008. Disponível em: <http:// www.juventudrebelde.cu/cuba/2008-12-28/intervencion-de-jose-luis-rodriguez-garcia-ministro-de-economia-y-planificacion/>. Acesso em: 02 jul.2018

GUTIÉRREZ, Marlén Sánchez. Endeudamiento externo cubano: el camino hacia la normalización. Cuba y la Economía, 2017. Disponível em: < https://cubayeconomia.blogspot. com/2017_01_28_archive.html>. Acesso : 02 jul.2018.

HIDALGO, Vilma; REYES Yaima Doimeadios. Dualidad Monetaria en Cuba: Causas e Implicaciones de Política Económica. Gest. Terc. Milen., 6 (11), 2003. Disponível em: <http://sisbib. unmsm.edu.pe/bibvirtual/publicaciones/administracion/v06_n11/dualidad.htm.>. Acesso em: 02 jul. 2018

HIDALGO, Vilma. Dualidade monetária em Cuba: A mudança que vem Entrevista. Fundação Mauricio Grabois, 2013. Disponível em: <http://grabois.org.br/portal/noticia.php?id_ sessao $=108$ id_noticia $=12426>$ Acesso em: 02 jul.2018. 
HIDALGO, Vilma. De la dolarización a la unificación monetária en Cuba, em Revista Economía y Desarrollo, No. 1 Vol. 143, jan-jun, 2008.

MAYBARDUK, Gary H. The Cuban Economy 15 Years Later: on firmer ground, but much still to do. Cuba in Transition: Volume 24, Papers and Proceedings of the Twenty-Fourth Annual Meeting, 2014. Disponível em: http://www.ascecuba.org/publications/annual-proceedings/ cuba-in-transition-volume-24/>. Acesso em: 02 jul.2018

MARTINEZ Paulo Henrique, Cuba: um balanço do Período Especial (1992-1998). Anais Eletrônicos do III Encontro da ANPHLAC. São Paulo,1998.

MENESES, Yaima Puig. Anuncian nuevas medidas para el trabajo por cuenta propia en Cuba. Cuba Debate, 2017. Disponível em: < http://www.cubadebate.cu/noticias/2017/08/01/la-gaceta-oficial-de-cuba-anuncia-nuevas-medidas-para-el-trabajo-por-cuenta-propia/>. Acesso em: 02 jul.2018.

MENESES, Yaima Puig; HERNÁNDEZ, Leticia Martínez. Emiten nuevos billetes de alta denominación, Granma, 2015. Disponível em: <http://www.granma.cu/cuba/2015-01-14/emiten-nuevos-billetes-de-alta-denominacion>. Acesso em: 02 jul.2018.

MESA-LAGO, Carmelo. ¿Termina la dualidad monetária en Cuba? Cubaencuentro, 2013. Disponível em: <https://www.cubaencuentro.com/txt/cuba/articulos/termina-la-dualidad-monetaria-en-cuba-283766>. Acesso em: 02 jul.2018.

MESA-LAGO, Carmelo. The Cuban Economy Today: Salvation or Damnation? Institute for Cuban and Cuban-American Studies University of Miami, 2005. Disponível em: <http://ctp. iccas.miami.edu/Research_Studies/CMesaLago2005.pdf>. Acesso em: 02 jul.2018.

MESA-LAGO, Carmelo. Growing Economic and Social Disparities in Cuba: Impact and Recommendations for Change. Institute for Cuban and Cuban-American Studies. University of Miami, 2002. Disponível em: $<$ http://ctp.iccas.miami.edu/research_studies/cmesalago.pdf $>$. Acesso em : 02 jul.2018

MESA-LAGO, Carmelo. La Dolarizacion de la Economia Cubana. Estudios Internacionales, Año 27, No. 107/108, N ${ }^{\circ}$ Especial: Cuba em El Sistema Internacional: Normalización y Reintegración (Julio-Septiembre/Octubre-Diciembre), 1994.

MOLINA, Jesús M. García. La reforma monetária en Cuba. Serie estudios y perspectivas, $\mathrm{n}^{\circ} 33$, mayo, 2005.

MORRIS, Emily. Unexpected Cuba. New Left Review, 88 jul-aug, 2014.

PECEQUILO, Cristina Soreanu; FORNER, Clarissa Nascimento. Os Estados Unidos e Cuba: Uma Agenda Intermestics. Boletim Meridiano, vol. 47, 2015.

PÉREZ, Silvia. Cuba en el CAME. Una integración extracontinental. Nueva Sociedad NRO. 68 sep-oct 1983.

PÉREZ, JR, Louis A. Cuba: Between Reform and Revolution. Third Edition Oxford University Press, 2006.

PÉREZ, Ladyrenee; REINALDO, Oscar Figueredo. En Cuba: Vender y Comprar Com Las Dos Monedas. Cuba Debate, 13 de janeiro, 2015.Disponível em: http://www.cubadebate.cu/especiales/2015/01/13/vender-comprar-y-ya-no-solo-en-cuc-fotos/\#.VSU8IPCYtfQ>. Acesso em: 02 jul.2018.

RAMONET, Ignacio. Fidel Castro: Biografia a Duas Vozes.. São Paulo: Boitempo Editorial, 2006.

ROQUE, Eduardo Hernández. Agregados monetários em la economía cubana. Banco Central de Cuba, s.d. Disponível em: < http://www.bc.gob.cu/Anteriores/Otros/InvestPolMon/Agregados\%20Monetarios.pdf $>$. Acesso em: 02 jul.2018.

SPADONI, Paolo. U.S. Financial Flows in the Cuban Economy. Transnational Law \& Contemporary Problems, vol. 14, n. 1, 2004.

TORRE, Augusto de la; IZE, Alain. La Unificación del Tipo de Cambio: El Caso Cubano. Cuba in Transition: Volume 24, Papers and Proceedings of the Twenty-Fourth Annual Meeting, 2014. Disponível em: http://www.ascecuba.org/publications/annual-proceedings/cuba-in-transition-volume-24/>. Acesso em: 02 jul.2018.

UGARTE, Joaquín Infante. La Dualidad Monetaria y Cambiaria, 2014. Edicion on line El economista de Cuba. Disponível em:< http://www.eleconomista.cubaweb.cu/2014/nro472/dualidad-monetaria.html>. Acesso em : 02 jul.2018.

VALLEJO, Oscar U-Echevarría. The Evolution of Cuba's Macroeconomy: From the Triumph of the Revolution through the Special Period. CAMPBELL, Al (ed) In: Cuban Economists on the Cuban Economy. University Press of Florida, 2013. 